\title{
A National survey on substance use among Iranian industrial workers
}

\author{
Behzad Damari*1미 ${ }^{1}$ Hamid Sarami ${ }^{2}$, Siamak Alikhani ${ }^{3}$, Hossein Mirzaei $^{4}$ \\ Received: 30 Jun 2019 \\ Published: 14 Mar 2020
}

\begin{abstract}
Background: Recent evidence shows that the prevalence of substance abuse is 2.1\% in Iranians aged 15-64 years, while reported rates are higher in studies that target industrial workplaces. Our study intends to provide a national picture of substance use among industrial workers in Iran.

Methods: This survey was designed to collect data through interviews and dipstick urine tests. Using a multi-stage sampling approach, we recruited our study subjects from a representative sample of industrial workers from all provinces in 2015. Data were weighted to estimate the prevalence rate of substance use. Odds ratios were calculated through adapting logistic regression to test the strength of association between substance use (based on self-report and urine test) and sociodemographic factors including sex, age group, education level, marital status and worker's professional training status. All statistical analyses were conducted using SPSS Version 22 . P $<0.05$ was considered significant.

Results: We analyzed the data collected from 13,128 participants; both self-reported use and urine test results. Majority of the respondents were male $(\mathrm{n}=12077,92 \%)$, aged $21-40$ years old $(\mathrm{n}=9491,72.3 \%)$, had finished middle/secondary school $(\mathrm{n}=8353,63.6 \%)$ and were married $(\mathrm{n}=11012,83.9 \%)$. Opium was the most popular abused substance $(\mathrm{n}=352,2.7 \%)$ followed by alcohol $(304,2.3 \%)$, based on self-reports. Urine tests showed that $23.8 \%(\mathrm{n}=3105)$ of the participants had a positive result for the use of opiates/opioids, crystal meth and/or cannabis. The highest rate of substance use reported from a province was $60.50 \%$; the lowest provincial rate was $9.0 \%$.

Conclusion: Nearly a one-fourth of Iranian industrial employees are engaged in use of substances with significant geographical distribution. Urine test is the recommended method to assess the prevalence of drug use among industrial workers in Iran.
\end{abstract}

Keywords: Survey, Substance Use, Industrial Workers, Iran

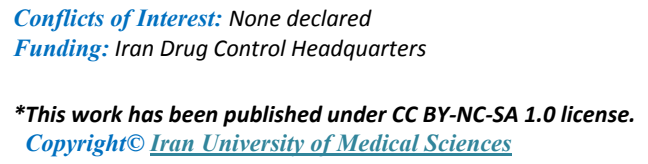

Cite this article as: Damari B, Sarami H, Alikhani S, Mirzaei H. A National survey on substance use among Iranian industrial workers. Med J Islam Repub Iran. 2020 (14 Mar); 34:20. https://doi.org/10.47176/mjiri.34.20

\section{Introduction}

In this context, substance (a combination of drugs and alcohol) abuse refers to WHO definition; substance abuse has

\footnotetext{
Corresponding author: Dr Behzad Damari, bdamari@tums.ac.ir

1. Department of Governance and Health, Neuroscience Institute, Tehran University of Medical Sciences, Tehran, Iran

2. Cultural planning and management Edalat University, Tehran, Iran

3. West Asian Health Academy, Vancouver, Canada

4. Department of Biostatistics and Epidemiology, School of Health, Kerman University of Medical Sciences, Kerman, Iran
}

referred to non-medical or unsanctioned patterns of use, irrespective of consequences. Thus, the definition published

$\uparrow$ What is "already known" in this topic:

The present study is the first study to investigate the prevalence of substance use among Iranian industrial workers at the national level.

\section{$\rightarrow$ What this article adds:}

Nearly quarter $(23.8 \%)$ of Iranian industrial workers have a history of substances use. Male gender, the 21-40 age groups, individuals with a less than primary school education and divorced or widow had greater odds of substance use based on their positive urine test. There was a significant difference between self-reported prevalence and estimates based on the urine test for cannabis, opiates/opioids, and crystal meth abuse. Urine test is the recommended method to assess the prevalence of drug use among industrial workers of Iran. 
in 1969 by the WHO Expert Committee on Drug Dependence was "persistent or sporadic excessive drug use inconsistent with or unrelated to acceptable medical practice" (1).

Illicit drug use is responsible for $1.9 \%(0.89 \%-1.3 \%)$ of total DALY (Disability Adjusted Life Years), and alcohol use is responsible for $0.7 \%(0.6-0.81)$ of total DALY (2). Substance use has significantly increased in the recent decade, especially among young people who are supposed to be the productive workforce (3).

Iran, like many other countries, has been dealing with the drug problem for a long time. In 2011, it was estimated that the prevalence of 12-month illicit drug use was $2.1 \%$ [approximately 1.12 million] among Iranians aged $15-64$ years (4). Alcohol consumption in Iran is limited because of cultural sensitivities, and the frequency of consumption within a one-year period is estimated to be $2.31 \%$ in those aged 15 and more (5).

According to literature, substance use, including alcohol consumption, has a negative impact on workplace safety (69). Studies have also demonstrated that various groups of industrial workers follow different patterns of substance use $(10,11)$.

A study conducted in 2002-2004 estimated that $8.2 \%$ of full-time workers in the United States aged 18-67 use illicit substances. It also found that one out of five people aged $18-25$ [19\%] had used drugs during the month before the study. Furthermore, men used substances more than women [9.7\% compared to $6.2 \%$ ] and the prevalence of substance use varied according to the job type (10).

Two studies have focused on the prevalence of illicit drug use in the industrial environments of Iran. The first one was conducted in natural gas fields (11), and the second one targeted the steel companies of Esfahan province in 2009, according to an unpublished report of Iranian Drug Control Headquarters. These studies presented an estimate of 15-25 percent of substance use. There is, however, no comprehensive nationwide study on the prevalence of substance use in the industrial environments of Iran, what the current study intends to reveal. It also aims to provide baseline information from industrial workplaces as the initial phase of a large-scale health intervention.

\section{Methods}

\section{Study design and sampling}

Following the protocol previously described (12), this cross-sectional survey was conducted from October to December 2015. The target population included employees of industrial plants throughout all provinces of Iran. The sample size estimated to be 13,489 workers using a multistage cluster sampling method. We first classified the existing national list of workplaces according to the size of their employees into 5 categories: 10-49, 50-99, 100-499, 500-999 and 1000 employees or more. Then the stratified samples were selected randomly from the payroll of 609 plants countrywide, proportional to the size of employees in each province. All those who participated in the study were legal employees, aged 18 years or above and had informed consent. Employees of small worksites with less than 10 workers, night-shift workers and workers of military industries were excluded.

\section{Instruments}

A confidential questionnaire and urine test kits for substance use detection were used to collect data.

Urine dipstick (Acon Labs) kits with relatively high sensitivity were used to biochemically trace substance use among the participants. The sensitivity and specificity of these kits reported as $99 \%$ and $95 \%$, respectively. Urine tests were applied on site after the interview part was completed. Kits were able to detect cannabis use up to 10 days before the test date while opium use could be traced if they were used in the past 4 days. The detection period for methamphetamine in the urine test was 3-5 days.

The results of urine tests were interpreted as positive, negative, and invalid based on the color change in the test and control lines of the applied strips.

\section{Data collection}

Urine sample collection was an immediate step after the interview and under the strict supervision of interviewers. Dipstick tests were applied on site.

\section{Statistical analysis}

We used the 2013 National Census of Industrial Workshops tool to weigh the survey data before estimating prevalence rates using Statistical Package of Social Studies Software [SPSS] version 22. Post-stratification weights were calculated based on age groups, sex and province of residence. $\mathrm{P}<0.05$ was considered significant. Odds ratios were calculated through adapting logistic regression to test the strength of association between substance use (based on self-report and urine test) and sociodemographic factors including sex, age group, education level, marital status and worker's professional training status.

The prevalence of opioid and opiate use was determined with a positive dipstick test result as well as a negative history of taking specific medications that could affect the test result. The prevalence of alcohol consumption and the use of other substances was determined by a positive self-report.

The study received its ethical approval from an ethics committee in the Research and Training Office, Drug Control Headquarters. The interviewers received training on privacy and confidentiality standards.

Informed consent was obtained from all participants included in the study to meet universal ethical standards.

\section{Results}

A total of 223 (1.7\%) employees refused to participate in an interview or to have their urine tested for substance use. Overall, 13,286 employees participated in the two steps of our study; however, we had to put aside 158 questionnaires $(1.2 \%)$ as some errors occurred during the testing process. Finally, we analyzed the data collected from 13,128 workers.

Majority of the respondents were male (92\%), aged 2140 years old $(72.3 \%)$, had finished middle/secondary school (63.6\%) and were married (83.9\%). About a third of the participants $(34.9 \%)$ were unskilled workers, while, 
Table 1. Demographic characteristics of the participants in the first national survey of substance abuse among industrial workers (Iran, 2015)

\begin{tabular}{llc}
\hline Variable & Level & $\mathrm{n}(\%)$ \\
\hline Sex & Male & $12077(92)$ \\
& Female & $1051(8)$ \\
Age group & $\leq 20 \mathrm{y} / \mathrm{o}$ & $107(0.8)$ \\
& $21-40 \mathrm{y} / \mathrm{o}$ & $9491(72.3)$ \\
& $41-60 \mathrm{y} / \mathrm{o}$ & $3478(26.5)$ \\
Education & $>60 \mathrm{y} / \mathrm{o}$ & $52(0.4)$ \\
& Primary school or lower & $1660(12.7)$ \\
& Middle school/ high & $8353(63.6)$ \\
& school & \\
& College or university de- & $3107(23.7)$ \\
Marital status & gree & \\
& Single & $2001(15.2)$ \\
& Married & $11012(83.9)$ \\
Worker's & Divorced or widow & $115(0.9)$ \\
class & Skilled worker* & $7508(57.2)$ \\
& Unskilled worker & $4579(34.9)$ \\
& Other** & $1041(7.9)$ \\
\hline
\end{tabular}

* Any worker who has attended a vocational training program at a high school, college, university or technical school.

** Applies to jobs with no available institutional training program.
$57.2 \%$ were skilled laborers. There were 2,325 (18\%) current tobacco smokers who had started smoking at $21 \pm 6$ years on average (Table 1 ).

Table 2 illustrates the prevalence of self-reported current use of various substances based on self-reports, and use prevalence supported by a positive urine dipstick test. Opium was the most popular substance used $(2.7 \%)$ followed by alcohol (2.3\%) based on self-reports. There was a significant difference between self-reported prevalence and estimates based on a urine test for cannabis, opiates/opioids, and crystal meth abuse. Overally, the prevalence of positive urine tests because of substance use was $23.8 \%$, whereas the prevalence estimate was $5.8 \%$ based on self-reports. The prevalence rates for multiple drug use (users of more than $1 \mathrm{drug}$ ) were $3.7 \%$ and $1.01 \%$ based on urine tests and interviews, respectively. No one reported using ecstasy, heroin crack or cocaine in the past 30 days before the study.

Male gender, less than primary school and divorced or

Table 2. Prevalence of substance use based on self-reports and urine tests in industrial workers (Iran, 2015)

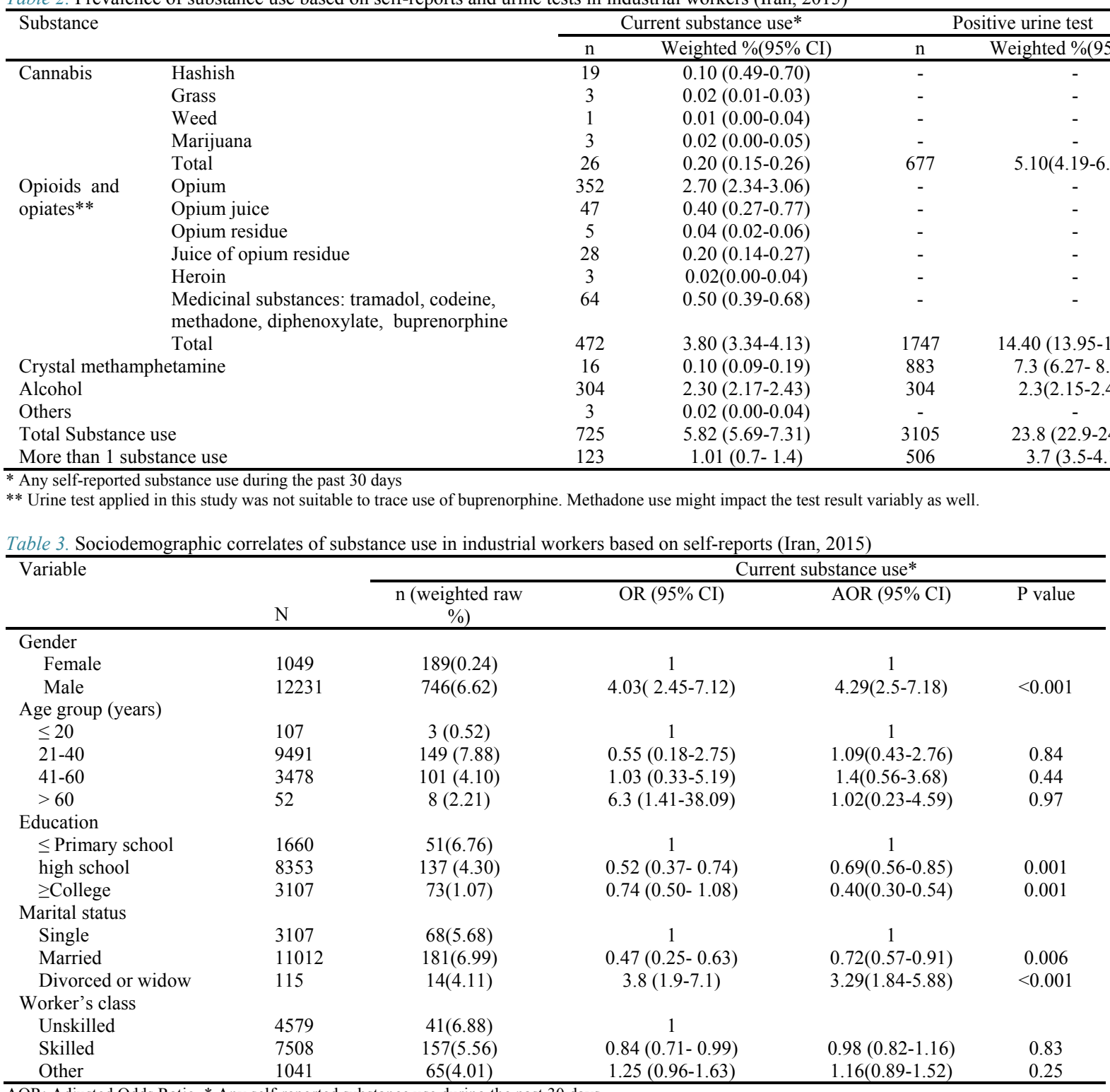


Table 4. Sociodemographic correlates of substance use in industrial workers based on urine test (Iran, 2015)

\begin{tabular}{|c|c|c|c|c|c|}
\hline \multirow[t]{2}{*}{ Variable } & \multirow[b]{2}{*}{$\mathrm{N}$} & \multirow[b]{2}{*}{$\mathrm{n}$ (weighted raw \%) } & \multicolumn{3}{|c|}{ Positive urine test } \\
\hline & & & OR (95\% CL) & AOR $(95 \% \mathrm{CI})$ & $\mathrm{P}$ value \\
\hline \multicolumn{6}{|l|}{ Gender } \\
\hline Female & 1049 & $132(4.70)$ & 1 & 1 & \\
\hline Male & 12231 & $2973(27.31)$ & $2.27(1.88-2.74)$ & $2.13(1.76-2.4597)$ & $<0.001$ \\
\hline \multicolumn{6}{|l|}{ Age group (years) } \\
\hline$\leq 20$ & 107 & $36(17.75)$ & 1 & 1 & \\
\hline $21-40$ & 9491 & $2352(27.21)$ & $2.12(1.18-3.80)$ & $2.12(1.17-3.85)$ & 0.043 \\
\hline $41-60$ & 3478 & $1054(21.10)$ & $2.6(1.45-4.67)$ & $2.38(1.14-7.12)$ & 0.128 \\
\hline$>60$ & 52 & $19(8.40)$ & $3.21(1.40-7.34)$ & $0.82(0.31-1.67)$ & 0.221 \\
\hline \multicolumn{6}{|l|}{ Education } \\
\hline$\leq$ Primary school & 1660 & $723(22.63)$ & 1 & 1 & \\
\hline high school & 8353 & $2305(26.19)$ & $0.85(0.75-0.96)$ & $097(0.8-1.03)$ & 0.17 \\
\hline$\geq$ College & 3107 & $434(14.54)$ & $0.50(0.43-0.57)$ & $0.57(0.49-0.67)$ & $<0.001$ \\
\hline \multicolumn{6}{|l|}{ Marital status } \\
\hline Single & 3107 & $251(25.01)$ & 1 & 1 & \\
\hline Married & 11012 & $2611(23.52)$ & $1.17(1.04-1.32)$ & $0.92(0.81-1.04)$ & 0.19 \\
\hline Other & 115 & $598(11.33)$ & $1.49(0.98-2.28)$ & $1.49(0.97-2.29)$ & 0.066 \\
\hline \multicolumn{6}{|l|}{ Worker's class } \\
\hline Unskilled & 4579 & 1181(19.41) & 1 & 1 & \\
\hline Skilled & 7508 & $1550(22.23)$ & $0.82(0.76-0.9)$ & $0.91(0.83-1.001)$ & 0.072 \\
\hline Other & 1041 & $731(25.30)$ & $1.15(0.99-1.33)$ & $1.09(0.93-1.27)$ & 0.26 \\
\hline
\end{tabular}

AOR: Adjusted Odds Ratio

widow had greater odds of substance use based on self-reports (Table 3)

Additionally, male gender, the $21-40$ age groups, individuals with less than primary school education and divorced or widow had greater odds of substance use based on their positive urine tests (Table 4).

Three provinces including Sistan and Baluchestan (60.5\%), Fars (43.4\%), and Kermanshah (35.9\%) had the highest rates, and West Azarbayjan (9.0\%), Qom (12.6\%) and Hamedan (12.7\%) represented the lowest use rates, respectively.

\section{Discussion}

The astonishing estimate of biochemically proven substance use (23.8\% of the target population) significantly outweighs the self-reported substance use rate $(5.82 \%)$. Also, self-reports revealed that opioids and opiates form the most commonly used group of substances (3.8\%). A simultaneous biochemical assessment confirms this predominance with $14.4 \%$ positive results. While opium is the most prominent drug used in the entire opioids and opiates group, and among all substances addressed in our study, alcohol is the second most reported substance used by industrial workers $(2.30 \%)$.

Male gender has a strong association with substance use. Although the number of female participants was rather low because of the actual contribution of women in industrial labor, we believe our post-stratification adjustments could properly enhance the accuracy of the analyses we made. In addition, this finding is supported by another national study on substance use that addressed the general adult population of Iran (4).

Another variable that affects substance use is age. This association was significant for those aged 21-40 years. The association of drug use and being middle-aged is also consistent with past Iranian studies (4) and opposite to the findings of some international studies that suggest a higher prevalence in younger ages $(13,14)$.

In addition, low education levels and unskilled workers are both factors that are associated with the problem.

It is obvious that substance use has a negative impact on employment and workforce participation (14). That is why drug testing in employment has become a routine practice with an increasing global trend (15); however, there are also doubts if testing is an effective approach, at least for workplace accident prevention (16). Using dipstick substance test and interview, our study was the first national survey that could provide unique baseline data on a major labor force problem; a crisis that is to be addressed by the Ministry of Health and the Ministry of Cooperatives, Labor, and Social Welfare through a comprehensive national intervention.

Studies on the prevalence of substance use during or before the work have yielded various results in different countries. In a study on substance use among 2,829 workers in the United States, $3.1 \%$ and 15\% reported experiencing substance and alcohol use, respectively, during work hours $(16,17)$. In Australia, the prevalence of the reported alcohol use in different job types varied from $3.1 \%$ to $56 \%$. Furthermore, the prevalence of substance use ranged from $6.6 \%$ to $46 \%(18-21)$.

Those who reported substance use are almost one-third of the entire employees diagnosed with substance use through biochemical tests (6.5 vs. $21.3 \%)$. A rather similar study in which morphine urine test was applied among employees of Asaluyeh Petrochemical Complexes, Iran, reported $23.3 \%$ substance use among the workers (11). In another study that was conducted by Iranian Drug Control Headquarters in some industrial plants of Isfahan in 2009 , it was reported $25.1 \%$ substance use, including $9.6 \%$ use of industrial opioids and stimulating drugs, and $15.5 \%$ for traditional substances such as opium. Additionally, the rate of alcohol consumption was $13.8 \%$.

A recent national household survey reported opioids and opiates as the most commonly abused substances among 15-64 years old Iranians. The prevalence of drug abuse based on DSM-IV and DSM-5 criteria were $2.09 \%$ and $2.44 \%$, respectively (4). Self-reported use is almost two 
times more in our study than the above general population survey; however, we didn't study the problem using criteria of a mental disorder. Also, methodological differences between the two studies should be taken into account before concluding that drug abuse is higher in the labor force. Another survey that reported alcohol use frequency among Iranian urban population, 15 years and more, reported a frequency of $2.31 \%$ that is consistent with our finding (5).

We also learned that interviews definitely underreport substance use when the results are compared with accurate biochemical tests in Iranian industrial workers. Similarly, studies from other nations have reported a significant difference between self-reports and urine tests or hair analysis (22). It is highly recommended though, to use urine tests as the best tracking tool for future studies regarding drug use in workplaces.

Substance use among workers is significantly diverse geographically and ranges from $9.0 \%$ in West Azarbayjan to $60.5 \%$ in Sistan and Baluchestan. As drug trafficking from Afghanistan is a major problem (22), this finding is consistent with what another recent study (4).

This study has some limitations. Researchers, for example, were not able to address unregistered workshops and places with less than 10 workers because the available databases used to design the study and to develop its operation do not include these. Also, sensitive issues such as drug problems are socially harder to investigate among women in a conservative cultural context. In addition, women's contribution to industrial labor market is poor. That is why the number of participating women was not comparable with their male peers. Furthermore, researchers had to use work premises to do interviews and apply dipstick tests that might not be an ideal place for such a sensitive study subject.

\section{Conclusion}

Nearly a one-fourth of Iranian industrial employees are engaged in use substances with significant geographical distribution. Urine test is the recommended method to assess the prevalence of drug use among industrial workers in Iran. There are various well- known psychological, behavioral, and social reasons for the tendency toward drugs and alcohol; therefore, we didn't spare further effort to undertake a correlation analysis though. We believe, however, policymakers need to take all the major risk factors and the determinants into account while addressing substance use through their joint intervention plan which is supposed to have highly relied on best practices in the health literature. For this purpose, the highly diverse geographical distribution of the problem should be reflected properly while planning interventions. Finally, the current study can serve as a basis to establish a national monitoring or surveillance mechanism for workplace drug abuse.

\section{Acknowledgements}

The authors appreciate for the people who contributed in project especial Hossein Almadani, Hassan Rafiei, Homan Narejiha, Iraj Esmaeili.
Conflict of Interests

The authors declare that they have no competing interests.

\section{References}

1. WHO. Lexicon of alcohol and drug terms. 1994.

2. Global Burden of Disease Study 2017. Global Burden of Disease Study 2017 (GBD 2017) Results. Seattle, United States: Institute for Health Metrics and Evaluation (IHME), 2018.

3. Melchior M, Chastang JF, Goldberg P, Fombonne E. High prevalence rates of tobacco, alcohol and drug use in adolescents and young adults in France: results from the GAZEL Youth study. Addict Behav. 2008;33(1):122-33.

4. Amin-Esmaeili M, Rahimi-Movaghar A, Sharifi V, Hajebi A, Radgoodarzi R, Mojtabai R, et al. Epidemiology of illicit drug use disorders in Iran: prevalence, correlates, comorbidity and service utilization results from the Iranian Mental Health Survey. Addiction. 2016;111(10):1836-47.

5. Nikfarjam A, Hajimaghsoudi S, Rastegari A, Haghdoost AA, Nasehi AA, Memaryan N, et al. The frequency of alcohol use in Iranian urban population: the results of a national network scale up survey. Int J Health Policy Manag. 2017;6(2):97.

6. Collins D, Lapsley HM. The costs of tobacco, alcohol and illicit drug abuse to Australian society in 2004/05: Department of Health and Ageing Canberra; 2008

7. Nicholson P, Mayho G, Sharp C. Alcohol, drugs and the workplacethe role of medical professionals. A briefing from the BMA Occupational Medicine Committee. 2nd Edition, July 2016.

8. Phillips M, Allsop S, Calogero C. Drugs and work: Responding to alcohol and other drug problems in Australian workplaces: IP Communications; 2001.

9. Pidd KJ, Berry JG, Roche AM, Harrison JE. Estimating the cost of alcohol-related absenteeism in the Australian workforce: the importance of consumption patterns. Med. J. Aust. 2006;185(1112):637-41.

10. Larson S, Eyerman J, Misty SF, Gfroerer, JC, Worker Substance Use and Workplace Policies and Programs/, Rockville, Md.: Department of Health and Human Services. Substance Abuse and Mental Health Services Administration, Office of Applied Studies. 2007. http://purl access gpo gov/GPO/LPS84606 (Accessed Feb 11, 2012). 2007.

11. Saberi-Zafarghandi M, Rahimi-Movaghar A, Amin-Esmaeili M, Razaghi E, Khastoo G, Jar-Siah R. Situation of Drug Use, Addiction and Related Services in the Laborers of Assaluyeh Industrial Area (South Pars Gas Field) in 2007. Hakim Res J. 2010;12(4):58-68.

12. Damari B, Almadani H, Ahmadi Pishkuhi M. Iranian drug use survey in workplaces: A study protocol. Med J Islam Repub Iran. 2018;32(1):537-44

13. Degenhardt L, Hall W. Extent of illicit drug use and dependence, and their contribution to the global burden of disease. Lancet. 2012;379(9810):55-70.

14. Degenhardt L, Whiteford HA, Ferrari AJ, Baxter AJ, Charlson FJ, Hall WD, et al. Global burden of disease attributable to illicit drug use and dependence: findings from the Global Burden of Disease Study 2010. Lancet. 2013;382(9904):1564-74.

15. Pidd K, Roche AM. How effective is drug testing as a workplace safety strategy? A systematic review of the evidence. Accid Anal Prev. 2014;71:154-65.

16. Frone MR. Prevalence and distribution of illicit drug use in the workforce and in the workplace: Findings and implications from a US National survey. J Appl Psychol. 2006;91(4):856.

17. Davey JD, Obst PL, Sheehan MC. Work demographics and officers' perceptions of the work environment which add to the prediction of at risk alcohol consumption within an Australian police sample. Policing. 2000;23(1):69-81.

18. Carruthers S, Boots K, Midford R. Perceived and self-reported licit and illicit drug use among fishing industry workers on the mid-north coast of Western Australia. Drug Alcohol Rev. 2002;21(4):357-61.

19. Davey J, Richards N, Freeman J. Fatigue and beyond: patterns of and motivations for illicit drug use among long-haul truck drivers. Traffic Inj Prev. 2007;8(3):253-9.

20. Pidd K, Boeckmann R, Morris M. Adolescents in transition: The role of workplace alcohol and other drug policies as a prevention strategy. Drugs (Abingdon Engl). 2006;13(4):353-65. 
Substance use among Iranian workers

21. Pidd K, Roche AM, Buisman-Pijlman F. Intoxicated workers: findings from a national Australian survey. Addiction. 2011;106(9):1623-33.

22. Cook RF, Bernstein AD, Andrews CM. Assessing drug use in the workplace: a comparison of self-report, urinalysis, and hair analysis. NIDA Res Monogr. 1997;167(247):72. 